\title{
Doença do disco intervertebral Hansen tipo II em cães: fisiopatologia, abordagem clínico-cirúrgica e controvérsias
}

\section{Hansen type II disc disease in dogs: pathophysiology, clinical- surgical approach and controversies}

\author{
Paulo Vinicius Tertuliano Marinho ${ }^{1 *}$; Mônica Vicky Bahr Arias ${ }^{2}$; \\ Carolina Camargo Zani³; Bruno Watanabe Minto ${ }^{4}$
}

Resumo

\begin{abstract}
A protrusão do disco intervertebral pode provocar compressão progressiva crônica da medula espinhal e os sinais neurológicos associados variam de acordo com a localização anatômica, duração e força dinâmica da compressão. A doença do disco tipo II não é totalmente compreendida, havendo muitas controvérsias sobre seu significado clínico e melhor forma de tratamento. $\mathrm{O}$ aspecto mais importante do tratamento conservador refere-se ao repouso associado à fisioterapia e exercícios leves, além de uso de corticoesteróides para diminuir o edema vasogênico. A descompressão medular por meio de cirurgia para remoção de material do disco do interior do canal medular é o tratamento cirúrgico de eleição na doença do disco tipo I, mas apresenta limitações quanto à técnica e ao resultado na doença do disco do tipo II. O objetivo deste trabalho é revisar a fisiopatologia e o tratamento da doença do disco intervertebral crônica e discutir as controvérsias existentes no tratamento médico bem como o uso de técnicas cirúrgicas tradicionais e novas técnicas.
\end{abstract}

Palavras-chave: Degeneração do disco intervertebral, medula espinhal, descompressão

\begin{abstract}
Protrusion of the intervertebral disc can cause chronic progressive compression of the spinal cord, and the neurological associated signs vary according to anatomical location, duration and dynamic force of compression. The type II disc disease is not fully understood, and there are many controversies about is clinical significance and best form of treatment. The most important aspect of conservative treatment is rest and physiotherapy associated with mild exercise, and use of corticosteroids to reduce vasogenic edema. The spinal decompression by surgery for removal of disc material from within the medullary canal is the surgical treatment of choice in type I disc disease, but has technical limitations in the type II disc disease. The purpose of this paper is to review the pathophysiology and treatment of chronic intervertebral disc disease and discuss the controversies in medical treatment and the use of some traditional and new surgical techniques.
\end{abstract}

Key words: Intervertebral disc degeneration, spinal cord, descompression

\footnotetext{
${ }^{1}$ Discente de Mestrado, Pesquisador, Universidade Estadual de Londrina, UEL, Londrina, PR. E-mail: paulo.veter@gmail.com

${ }^{2}$ Prof $^{\mathrm{a}} \mathrm{Dr}^{\mathrm{a}}$ da UEL, Londrina, PR. E-mail: vicky@uel.br

${ }^{3}$ Discente de Mestrado, Pesquisador, UEL, Londrina, PR. E-mail: carolzani_vet@yahoo.com.br

${ }^{4}$ Prof. da Faculdade de Ciências Agrárias e Veterinária, FCAV/UNESP, Jaboticabal, SP. E-mail: brunobtu@yahoo.com.br

* Autor para correspondência
} 


\section{Introdução}

Os discos intervertebrais são estruturas de conteúdo gelatinoso com a função principal de conectar as vértebras, fornecer flexibilidade à coluna vertebral e absorver impactos. Estão localizados entre os corpos vertebrais de todas as vértebras, com exceção apenas de C1-C2 (atlas e áxis) e das vértebras sacrais (BRAY; BURBRIDGE, 1998a; DA COSTA, 2001; SHARP; WHEELER, 2005a).

A incapacidade do disco intervertebral de cumprir a sua função fisiológica interfere com a ação normal da coluna vertebral, de forma a influenciar outros componentes, tais como ligamentos, articulações e os corpos vertebrais. A degeneração do disco intervertebral gera deficiências na qualidade e integridade biomecânica do disco intervertebral levando a falha estrutural da unidade funcional da coluna vertebral, podendo causar ainda a compressão da medula espinhal (BERGKNUT et al., 2013).

A degeneração do disco intervertebral pode causar extrusão (Hansen tipo I) do material discal para o interior do canal vertebral, mais frequente em raças condrodistróficas, ou protrusão (Hansen tipo II), principalmente em cães de raças grandes ou não condrodistróficas, sendo ambas responsáveis por sinais neurológicos que variam na dependência da localização anatômica, duração e força dinâmica da compressão (BRAUND, 1996; BAHR ARIAS; SEVERO; TUDURY, 2007).

Apesar do seu reconhecimento precoce (HANSEN, 1952), a protrusão do disco toracolombar (Hansen tipo II) não tem sido abordada claramente em alguns aspectos na literatura veterinária (MACIAS et al., 2002). Embora não tão frequente como as extrusões agudas, a protrusão de disco é também uma causa de doença medular em cães de raças grandes (CUDIA; DUVAL, 1997).

A lesão medular causada pela protrusão anular pode resultar em incapacidade permanente e seu tratamento ainda permanece um desafio, principalmente por que não se sabe a melhor forma de tratamento desta afecção. $O$ conhecimento da fisiopatogenia, do significado deste tipo de compressão, dos principais diagnósticos diferenciais e doenças concomitantes, e talvez a utilização de técnicas cirúrgicas específicas, podem fazer diferença quanto ao retorno à deambulação. $\mathrm{O}$ objetivo desta revisão é abordar a fisiopatologia e o tratamento da doença do disco intervertebral tipo II e discutir as controvérsias existentes sobre o uso de algumas técnicas cirúrgicas tradicionais, bem como de novas técnicas cirúrgicas.

\section{Degeneração do Disco Intervertebral}

A degeneração do disco intervertebral é um processo normal que se desenvolve com a idade do animal (BRISSON, 2010), mas que posteriormente pode ocasionar a doença do disco intervertebral (DDIV) (OLBY; JEFFERY, 2012). Há dois tipos básicos de degeneração do disco, denominadas metaplasia condróide e metaplasia fibróide, provocando dois tipos distintos de doença do disco (SHARP; WHEELER, 2005a; DEWEY, 2008).

\section{Metaplasia condroide}

A metaplasia condroide é caracterizada por perda de glicosaminoglicanos específicos do núcleo pulposo (NP), aumento do teor de colágeno e redução no teor de água, o que pode resultar em perda das propriedades hidroelásticas e da capacidade de resistir à pressão. A transformação progressiva do NP gelatinoso para cartilagem hialina pode começar aos dois meses de idade em Dachshunds, e envolve a substituição de células mesenquimais do NP por células do tipo condrócito. Cães condrodistróficos têm 75 a 90\% do seu NP gelatinoso transformado em cartilagem hialina com um ano de idade, enquanto que cães não condrodistróficos mantém elevados níveis de proteína não colagenosa durante o envelhecimento (BRISSON, 2010). O processo começa na zona perinuclear e acaba se difundindo 
para a maior parte do NP e para o interior do anel fibroso (AF). Com o passar do tempo, as alterações degenerativas observadas no núcleo são desintegração da matriz, calcificação periférica ou central e áreas localizadas de morte celular. Fendas e fissuras radiais podem surgir no anel fibroso (BRAUND, 1996). O NP gelatinoso e transparente é transformado da coloração cinza-branco para um tecido amarelo fibrocartilaginoso (BRISSON, 2010).

A metaplasia condroide pode ocorrer ao longo dos discos de toda a coluna vertebral. Um total de 24 a 90\% dos Teckels desenvolvem mineralização de um ou mais disco intervertebrais, com uma média de 2,3 discos calcificados por cão. Calcificações foram relatadas em todos os discos, mas os discos da região torácica caudal, especialmente entre T10 e T13, costumam ser mais afetados (BRISSON, 2010). Embora seja mais comum em raças condrodistróficas e com tendências condrodistróficas como o Poodle miniatura e Cocker Spaniel, a degeneração condroide e a extrusão de disco podem ocorrer em qualquer raça de cães, inclusive de grande porte (LE COUTEUR; GRANDY, 2004).

\section{Metaplasia fibrosa}

Metaplasia fibrosa é um processo degenerativo relacionado com a idade que ocorre independentemente de raça, mas está documentado mais comumente em cães não condrodistróficos a partir de sete anos de idade. Caracteriza-se por desidratação do NP com degeneração concorrente do anel fibroso e substituição do núcleo por fibrocartilagem (DE LAHUNTA; GLASS, 2009; BRISSON, 2010). Pode ocorrer em qualquer disco intervertebral ao longo da coluna vertebral. A metaplasia fibrosa, insidiosa e lenta, deixa o disco com níveis mais elevados de glicosaminoglicanos e conteúdo mais baixo de colágeno, comparativamente aos discos condrodistróficos. Este processo degenerativo leva ao abaulamento do NP dentro do AF enfraquecido, finalmente ocorrendo protrusão dorsal do disco intervertebral (SMOLDERS et al., 2013). Ao contrário da metaplasia condroide, a degeneração fibroide afeta apenas um pequeno número de discos e a mineralização não é frequente. Um total de 40 a $60 \%$ dos cães com sete anos de idade ou mais velhos mostram evidência bioquímica de degeneração do NP (BRISSON, 2010).

Embora os estudos post-mortem de Hansen (1952) tenham sugerido que extrusões tipo I ocorrem mais comumente em raças condrodistróficas e que protrusões tipo II em raças não condrodistróficas, em estudos mais recentes (BRISSON, 2010) foi comprovado que 62 a $92 \%$ dos cães não condrodistróficos pesando mais de $20 \mathrm{~kg}$ com doença do disco intervertebral (DDIV) toracolombar apresentaram extrusão do material nuclear ao invés de protrusão. Cães condrodistróficos também podem desenvolver Hansen tipo II com protrusão anular, mas isso é menos comum (BRISSON, 2010).

\section{Classificação da Doença do Disco Intervertebral}

\section{Hansen tipo I}

Historicamente, a degeneração do disco intervertebral com ruptura do AF e extrusão do NP foi caracterizada como causa de compressão da medula espinhal desde 1930 (HANSEN, 1952, 1966). É considerada a causa mais comum de lesão severa da medula espinhal em cães e estima-se que acometa em torno de $1 \%$ de todos os casos vistos na clínica de pequenos animais (OLBY et al., 2001).

Alguns cães com doença aguda do disco intervertebral são apresentados somente com dor, sem a presença de outras alterações neurológicas. Outros sofrem lesão concussiva e compressiva grave da medula espinhal em consequência da extrusão de disco e podem ter vários graus de lesão medular, assim as manifestações clínicas dependem da localização e da gravidade da lesão (TAYLOR, 2010). A extrusão do disco intervertebral está tipicamente associada com a degeneração condroide 
e envolve a migração hiperaguda do material do núcleo pulposo através de todas as camadas do AF rompido para o interior do canal vertebral (OLBY; JEFFERY, 2012). As forças anormais geradas pela degeneração e mineralização do NP levam ao desenvolvimento de ruptura do $\mathrm{AF}$, com quebra de cada camada formando um túnel do qual o NP anormal pode eventualmente deslocar-se para o interior do canal medular (HANSEN, 1952, 1966; DE LAHUNTA; GLASS, 2009; BRISSON, 2010) ocasionando os sinais clínicos devido à compressão medular focal e em alguns casos da raiz do nervo espinhal (TOOMBS; WATERS, 2007).

O material nuclear pode estar disperso por um segmento grande da medula espinhal, ou localizado, em estreita proximidade com o espaço ocupado pelo disco afetado. A ruptura pode ser lateral ao ligamento longitudinal dorsal, podendo ocorrer uma extrusão de forma irregular, plana, em padrão circular ou cônico. O material do disco que sofreu extrusão é irregular, quebradiço, granulado, às vezes parece gesso e varia de branco-amarelo para cinza-amarelo ou mesmo cinza-vermelho se houver a presença de sangue misturado, devido à consequente lesão do seio venoso na DDIV em cães (BRISSON, 2010). Quando esta extrusão se torna crônica, em geral por não ter sido realizado o tratamento cirúrgico, o material do núcleo pulposo fibrinoso pode aderir-se à dura-máter ou pode ser reabsorvido (BRISSON, 2010).

\section{Hansen tipo II}

A protrusão do disco intervertebral resulta na formação de uma protuberância arredondada e lisa na superfície dorsal do disco, em direção ao canal vertebral, raramente aderida à dura máter (HANSEN, 1952, 1966; LORENZ; KORNEGAY, 2006; DE LAHUNTA; GLASS, 2009; BRISSON, 2010). Essa protrusão parcial parece causar trauma medular repetitivo causando sinais lentamente progressivos de compressão da medula espinhal, sendo mais comum em cães idosos de raças de grande porte, principalmente o Pastor Alemão (MACIAS et al., 2002) e o Dobermann (OLBY; JEFFERY, 2012), mas pode acometer raças de pequeno porte (DEWEY, 2008; TAYLOR, 2010), sendo descrita em Chihuahua, Yorkshire e Maltês (OLBY; JEFFERY, 2012). Ocorre principalmente nas regiões cervical caudal (OLBY; JEFFERY, 2012), associada ou não à espondilomielopatia cervical (DA COSTA, 2010; SCHMIED, GOLINI; STEFFEN, 2011), lombo sacra (AMORT et al., 2012; SMOLDERS et al., 2013) e toracolombar (MACIAS et al., 2002; DE LAHUNTA; GLASS, 2009). Segundo Schmied, Golin e Steffen (2011), raças grandes apresentam DDIV do tipo II principalmente entre C6-C7. Quando associada à espondilomielopatia cervical caudal, observase más formações vertebrais caracterizadas por encurtamento e mau alinhamento com deslocamento da porção cranial da vértebra dorsalmente no canal vertebral (SCHMIED; GOLINI; STEFFEN, 2011). Em um estudo realizado por Cudia e Duval (1997) com 62 cães não condrodistróficos, a maioria dos animais apresentou extrusão do disco, mas dos cinco animais que apresentaram protrusão anular, o espaço L1-L2 foi o mais afetado. Nesses locais da coluna vertebral o disco intervertebral pode ser submetido a cargas e tensões excessivas, resultando em desgaste em longo prazo e posterior degeneração, resultando em falha estrutural e herniação tipo II do disco intervertebral (SMOLDERS et al., 2013).

Em cães condrodistróficos, a extrusão do disco é 11,3 vezes mais frequente que a protrusão, enquanto que nos pacientes não condrodistróficos, a extrusão é 1,5 vezes menos frequente que a protrusão (KRANENBURG et al., 2013). A presença do ligamento intercapital entre as costelas fornece um suporte adicional ao ligamento longitudinal dorsal, sendo a incidência de herniação de disco na região torácica cranial extremante baixa, entretanto em três cães Pastor Alemão diagnosticou-se protrusão anular entre as vértebras T2-T3 (GAITERO; AÑOR, 2009). 


\section{Fisiopatologia da Compressão Medular Crônica}

Quando ocorre protrusão do disco intervertebral ou extrusão não operada, a consequência é a compressão medular crônica, porém na extrusão não operada, a lesão inicial é do tipo aguda, inclusive podendo haver concussão medular (OLBY, 2010). Já a protrusão anular causa compressão lentamente progressiva da medula espinhal, cujos efeitos são mais predominantes na substância branca, geralmente não havendo contusão concomitante da medula espinhal. A compressão medular crônica pode resultar em atrofia medular com lesão irreversível dos axônios, do tecido de suporte e da vascularização (MACIAS et al., 2002; XU et al., 2008; OLBY; JEFFERY, 2012).

Quando há extrusão aguda de pequeno volume de material discal para o interior do canal vertebral, há produção de uma força dinâmica mínima, levando assim a sinais clínicos brandos. Na compressão crônica a força dinâmica é baixa e a medula espinhal pode lançar mão de mecanismos compensatórios ao deslocamento que se desenvolveu, induzindo mudanças em sua forma. Quando a compressão supera este mecanismo, desenvolve-se hipóxia local, assim como desmielinização, degeneração axonal e malácia (TOOMBS; WATERS, 2007). Por isso, existem diversas diferenças fisiológicas entre a compressão medular aguda e a crônica. $\mathrm{Na}$ compressão crônica, o fluxo sanguíneo e os níveis de oxigênio são frequentemente mantidos na medula espinhal, e a principal alteração que ocorre nestes casos é a desmielinização e edema axonal e, somente mais tarde ocorre edema vasogênico da substância branca, o que por sua vez aumenta a compressão medular (PLATT; ABRAMSON; GAROSI, 2005). As diferenças entre os mecanismos das lesões aguda e crônica à medula espinhal também podem ter relação com o tipo de vaso afetado pela lesão, pois durante a doença compressiva crônica, as veias são mais comprometidas do que as artérias (JEFFERY, 1995; BAHR ARIAS; SEVERO; TUDURY, 2007).

Frequentemente, as alterações patológicas de compressão crônica da medula espinhal ficam confinadas à substância branca. $\mathrm{O}$ dano é maior nas colunas laterais, intermediário nas colunas ventrais, e menos evidente nas colunas dorsais. Os tratos motores mais calibrosos são mais sensíveis à compressão crônica que as fibras sensoriais menos calibrosas; dessa forma, a ocorrência de paresia é comum e a perda sensorial é rara em casos de compressão progressiva crônica (TOOMBS; WATERS, 2007). Há o predomínio de lesões como desmielinização e degeneração walleriana nos tratos espinhais da substância branca, porém também pode existir dano à substância cinzenta, provavelmente devido à isquemia progressiva (BAHR ARIAS; SEVERO; TUDURY, 2007).

Dois fatores são responsáveis pelos sinais clínicos vistos na compressão medular crônica: a força mecânica direta e o suprimento sanguíneo comprometido (BAHR ARIAS; SEVERO; TUDURY, 2007). A deformidade mecânica da medula espinhal decorre de sua constituição por tecido macio e delicado, e a força mecânica é capaz de alterar a condução normal de impulsos nervosos (JEFFERY, 1995; KRAUS, 2000).

Não obstante, a lesão medular crônica também pode se referir aos efeitos do trauma medular meses a anos após a lesão medular aguda, principalmente a desmielinização (BLIGHT, 2000). Os avanços nos cuidados médicos, no controle das infecções secundárias que podem se desenvolver após o trauma e a capacidade de lidar com todas as complicações da lesão medular promoveu o aumento da sobrevida dos pacientes com este tipo de lesão, gerando a existência dos "lesados medulares crônicos", principalmente na medicina humana, incentivando a pesquisa de terapias para o tratamento da desmielinização crônica (BLIGHT, 2000; BAHR ARIAS; SEVERO; TUDURY, 2007).

\section{Apresentação Clínica}

Quando a DDIV tipo II ocorre nos segmentos medulares toracolombares, constata-se ataxia 
proprioceptiva, paraparesia ambulatorial, reações posturais deprimidas ou ausentes nos membros pélvicos, hiper-reflexia dos membros pélvicos e dor à palpação epaxial. É mais descrita em cães da raça Pastor Alemão (MACIAS et al., 2002). O histórico do paciente é de uma doença lentamente progressiva, entre dois e seis meses de duração (GAITERO; AÑOR, 2008). Embora os sinais dos membros pélvicos sejam, com frequência, bilateralmente simétricos, podem ocorrer sinais assimétricos (TOOMBS; WATERS, 2007; DE LAHUNTA; GLASS, 2009; BRISSON, 2010). A paraplegia sem nocicepção é infrequente na doença do disco tipo II (MACIAS et al., 2002).

Animais com sinais clínicos menos graves podem manter a coluna ligeiramente arqueada dorsalmente (cifose), podendo mostrar-se relutantes em caminhar. Geralmente, o reflexo cutâneo do tronco está reduzido ao longo da coluna dorsal, caudalmente ao sítio da lesão, mas pode haver hiperpatia no local da lesão ou cranialmente a ela, que pode ser demonstrada por pressão digital sobre a coluna no local da protrusão (BRAUND, 1996; TOOMBS; WATERS, 2007).

Nos cães daraça Dobermann, Rottweiler, Dálmata e Labrador entre outros, a protrusão anular ocorre principalmente na região cervical caudal, associada ou não à espondilomielopatia cervical, e os animais apresentam ataxia proprioceptiva mais aparente nos membros posteriores, com fraqueza ou ataxia dos membros torácicos, podendo ainda haver dor cervical (DA COSTA, 2010; SCHMIED; GOLINI, STEFFEN, 2011). Na avaliação dos reflexos podese detectar tanto uma síndrome medular cervical como cervicotorácica (DA COSTA, 2010).

$\mathrm{Na}$ protrusão de disco lombo sacra, comum em cães da raça Pastor Alemão, pode haver histórico de dor ao toque da região lombar, dor espontânea, incontinência urinária e/ou fecal e automutilação da cauda. Estes sinais podem ser causados somente pela protrusão de disco, mas podem também ser decorrentes da síndrome da cauda equina associada à estenose lombosacra, em que além da protrusão do disco, ocorre má articulação entre a vértebra lombar e sacral, hipertrofia dos processos articulares e do ligamento amarelo (JEFFERY, 1995; SHARP; WHEELER, 2005c; DE LAHUNTA; GLASS, 2009).

\section{Diagnóstico Diferencial}

Muitas doenças vertebro-medulares podem causar sinais clínicos similares à doença do disco intervertebral crônica, sendo os principais diferenciais na região toracolombar as neoplasias medulares, divertículo subaracnóideo e a mielopatia degenerativa (MD) (DE LAHUNTA; GLASS, 2009). A MD pode ocorrer concomitantemente à DDIV do tipo II. A MD é uma doença degenerativa que atinge com certa frequência cães da raça Pastor Alemão, Boxer, Golden Retriever, Rodesianos e Poodle gigante entre outras. Deve-se ter experiência clínica para evitar a indicação de uma cirurgia descompressiva em cães com DDIV do tipo II que possam também ter MD. O uso de corticóides em dose anti-inflamatória por um curto período pode ajudar a distinguir entre estas duas afecções (DE LAHUNTA; GLASS, 2009). $\mathrm{Na}$ região lombo sacra e cervical os principais diagnósticos diferenciais para quadros crônicos progressivos, com dor, são a discoespondilite, divertículo subaracnóideo e neoplasias vertebromedulares (SHARP; WHEELER, 2005c; DE LAHUNTA; GLASS, 2009).

Para complicar a situação destes pacientes com doença do disco intervertebral do tipo II, é frequente a presença de condições ortopédicas concomitantemente aos distúrbios neurológicos, como a displasia coxofemoral e a ruptura do ligamento cruzado cranial. Estas doenças ocorrem frequentemente em cães idosos de raças grandes e gigantes, no entanto por mais grave que seja uma doença músculo esquelética, esta não causa ataxia proprioceptiva (JEFFERY, 1995). É importante o diagnóstico dessas afecções para que sejam adequadamente tratadas. 


\section{Exames complementares}

O diagnóstico é realizado com base na resenha, história, sinais clínicos e resultado dos exames complementares (BRISSON, 2010). A radiografia simples não é o exame mais indicado para o diagnóstico da doença do disco tipo II, mas pode ser sensível na identificação da redução do espaço intervertebral e presença de material calcificado dentro do canal medular observados na doença do tipo I (BRISSON, 2010). Deve ser realizada para excluir discoespondilite e neoplasias vertebrais que causam lise óssea e que podem inicialmente causar alguns sinais clínicos similares a DDIV tipo II (COATES, 2004). A espondilose deformante é um achado comum nas radiografias simples da coluna vertebral toracolombar e lombosacra de cães idosos de raças grandes, mas não está associada com compressão medular, entretanto, pode estar associada com maior incidência de protrusão anular (LEVINE et al., 2006; DE LAHUNTA; GLASS, 2009). Em um estudo com cães de raças grandes e DDIV II, as alterações mais frequentes foram esclerose das placas vertebrais terminais e espondilose deformante em mais de um local simultaneamente, sendo a alteração menos frequente a diminuição do espaço intervertebral (MACIAS et al., 2002).

Recomenda-se a realização dos seguintes exames para descartar outras doenças medulares: hemograma, bioquímica sérica completa, urinálise, PCR para agentes infecciosos do sangue e líquor e radiografias torácicas, que em geral são normais (DE LAHUNTA; GLASS, 2009). A análise do líquido cérebro-espinhal auxilia no diagnóstico ou exclusão de meningomielites infecciosas e inflamatórias. Deve-se relacionar este achado com a localização da síndrome medular, história e sinais clínicos (DE LAHUNTA; GLASS, 2009).

A mielografia é considerada um meio de diagnóstico bastante acurado para o diagnóstico da doença do disco intervertebral em cães, inclusive determinando o lado correto em 89 a $100 \%$ dos cães (KERWIN; LEVINE; HICKS, 2012). A alteração mais observada na mielografia é o desvio focal da coluna de contraste, em direção dorsal ou dorsolateral, podendo haver lateralização do desvio na projeção ventrodorsal (MACIAS et al., 2002). Em um estudo com cães apresentando DDIV cervical tipo II, os sinais mielográficos que levaram à suspeita da doença foram desvio dorsolateral ou dorsal focalizado do contraste e leve adelgaçamento da coluna de contraste sobre o disco afetado (SCHMIED; GOLINI; STEFFEN, 2011). Apesar de cães de raças pequenas com extrusão de disco tenderem a ter uma única lesão na mielografia, em um estudo foi observado que $47 \%$ dos cães de raças grandes com herniação do tipo II apresentam na mielografia várias protrusões simultâneas (HASHIMOTO et al., 1990; BRISSON, 2010), dificultando o diagnóstico e a escolha do tratamento, pois não se sabe o real significado destas múltiplas protrusões.

Em três cães da raça Pastor Alemão com DDIV do tipo II, após a realização da mielografia foi realizada a tomografia computadorizada, que auxiliou no diagnóstico da compressão medular de origem extradural, inclusive facilitando a identificação de lateralização da compressão (GAITERO; AÑOR, 2008).

A Ressonância Magnética (RM) permite a identificação da degeneração do disco e diferenciação entre DDIV tipo I e II, permitindo ainda a identificação de alterações estruturais no interior da medula espinhal e espaço epidural (KERWIN; LEVINE; HICKS, 2012). O diagnóstico diferencial com outras doenças neoplásicas, inflamatórias e vasculares, que podem mimetizar a DDIV também é facilitado com o uso da RM (KERWIN; LEVINE; HICKS, 2012). Na RM de cães com DDIV cervical tipo II o diagnóstico foi realizado com base na presença de protrusão de disco em direção central, à direita ou esquerda, às vezes com alteração focal no anel fibroso, sem material do disco no espaço epidural, mas a intensidade do sinal do material do disco foi hipointensa em $\mathrm{T} 2$ na maioria dos cães 
(SCHMIED; GOLINI, STEFFEN, 2011).

Entretanto, para De Lahunta e Glass (2009), a $\mathrm{MD}$ é a doença mais importante no diagnóstico diferencial da protrusão de disco, sendo muito comum que Pastores Alemães com MD apresentem mais de uma protrusão identificada na ressonância magnética. Segundo Macias et al. (2002), 47\% dos cães grandes podem ter múltiplas protrusões. Para De Lahunta e Glass (2009), cães Pastores Alemães, com mais de cinco anos, apresentando paraparesia espástica lentamente progressiva, apresentam MD até prova em contrário.

\section{Tratamento}

ADDIV tipo II podesertratadacommedicamentos ou cirurgia, mas há várias controvérsias sobre o melhor tipo de tratamento (MACIAS et al., 2002). O prognóstico é significativamente pior em pacientes com protrusão em comparação a pacientes com compressão medular secundária à extrusão do disco intervertebral, pela dificuldade de remoção cirúrgica do ânulo fibroso hipertrofiado através de anulectomia parcial sem causar lesão iatrogênica da medula e seios venosos, e também pelo fato da compressão medular ser crônica, o que pode causar lesão irreversível ao tecido nervoso (KANCHIKU et al., 2001; MACIAS et al., 2002).

\section{Tratamento Clínico}

As indicações gerais para o tratamento clínico da DDIV crônica são: episódio de dor ou dor com leve paresia; situação financeira do proprietário e presença de afecção sistêmica grave ou distúrbios graves de outros órgãos que contraindiquem a realização da cirurgia (BRAUND, 1996; TOOMBS; WATERS, 2007).

Os cuidados de enfermagem nesses pacientes são muito importantes. Os elementos fundamentais desta terapia auxiliar incluem: restrição da atividade física; acesso à água e ao alimento com monitoração do consumo; banhos regulares combinados com manutenção de uma cama macia e seca para evitar assadura por urina e úlceras de decúbito; supervisão, assistência e monitoração da micção e da defecação; fisioterapia conduzida com rigor para manutenção da massa muscular e da amplitude dos movimentos articulares e acupuntura (TOOMBS; WATERS, 2007).

Os glicocorticoides podem ser utilizados em dose anti-inflamatória no tratamento de condições crônicas que causam compressão à medula espinhal para redução do edema vasogênico, diminuindo o efeito compressivo, apresentando ainda, efeito anti-prostaglandina, reduzindo a inflamação das raízes nervosas e a isquemia, aliviando assim a dor (JEFFERY, 1995; BAHR ARIAS; SEVERO; TUDURY, 2007). Tais medicamentos podem ser benéficos para os animais com leve paresia, pela redução da inflamação e da formação de radicais livres de oxigênio e por auxiliar na redução da isquemia tecidual, hipoxia e edema, o que, em caso contrário, poderia levar à desmielinização (BRAUND, 1996). Segundo Da Costa (2001), o uso de prednisona $(0,5 \mathrm{mg} / \mathrm{kg}$ a cada 24 horas durante 15 dias dias seguido de $0,5 \mathrm{mg} / \mathrm{kg}$ a cada 48 horas durante mais 15 dias) é recomendado nesses casos.

Anti-inflamatórios não esteroidais podem ser empregados como parte da terapia para animais que apresentam dor ou leve paresia (JEFFERY, 1995; TOOMBS; WATERS, 2007). O maior problema do uso de anti-inflamatórios não esteroidais (AINEs) é observado quando os mesmos não surtem efeito e o medico veterinário opta por utilizar em seguida os glicocorticoides, o que pode causar sérias complicações gastrintestinais com o uso seguido dessas duas drogas (BAHR ARIAS; SEVERO; TUDURY, 2007). Opioides como morfina, oximorfina e butorfanol (SHARP; WHELLER, 2005b), uso de acupuntura (CHAN; LIN; ROGERS, 1996) e medicamentos anticonvulsivantes como gabapentina e pregabalina (MUSK; RAISIS, 2012) são opções adequadas para o tratamento da dor neuropática. 


\section{Tratamento Cirúrgico}

Na DDIV do tipo I, o principal objetivo do tratamento cirúrgico é a descompressão da medula espinhal para remoção do material do disco que comprime a medula espinhal e/ou raízes nervosas (BAHRARIAS etal., 2007). Aobtenção de resultados favoráveis depende de intervenção precoce e técnica cirúrgica cuidadosa (MOISSONNIER; MEHEUST; CARROZO, 2004; TOOMBS; WATERS, 2007). Entretanto, na cirurgia de pacientes com DDIV do tipo II, observa-se o material protruído firmemente aderido aos remanescentes do anel fibroso, seios venosos e dura-máter (INOUE, 1981; BRAY; BURDRIDGE, 1998b; SEIM, 2008) e sua retirada cirúrgica por técnicas tradicionais de descompressão requer manipulação substancial da medula espinhal, para que esta seja adequadamente descomprimida, o que pode influenciar negativamente no prognóstico neurológico (MACIAS et al., 2002).

\section{Descompressão da Medula}

A abertura do canal medular para a retirada do material do disco do interior do canal medular é a modalidade de tratamento mais indicada para pacientes com déficits neurológicos graves ou progressivos e também tem sido recomendada para pacientes com déficits neurológicos leves ou apenas dor epaxial (BRISSON, 2010). Na doença do disco tipo I, a remoção completa do material de disco é associada a resultado clínico positivo, mesmo nos casos de cães com paraplegia e perda da nocicepção (BAHR ARIAS et al., 2007).

Os procedimentos indicados para descompressão da medula espinhal cervical são a laminectomia dorsal, o "slot" ou fenda ventral (BRISSON 2010, DA COSTA, 2010) e a hemilaminectomia (SCHMIED; GOLINI; STEFFEN, 2011). Na coluna vertebral lombo-sacra, o procedimento mais indicado é a laminectomia dorsal, associado ou não à estabilização vertebral (SLOCUM; DEVINE, 1986). Os procedimentos tradicionalmente usados para descomprimir a medula espinhal toracolombar e as raízes nervosas são: laminectomia dorsal (TOOMBS; WATERS, 2007; SEIM, 2008; BRISSON, 2010) e hemilaminectomia (DA COSTA, 2001; TOOMBS; WATERS, 2007; SEIM, 2008; BRISSON, 2010).

Procedimentos como pediculectomia/ minihemilaminectomia (BITTELO; THACHER, 1987; JEFFERY, 1988; LUBBE; KIRBERGER; VERSTRAETE, 1994; DA COSTA, 2001; SHARP; WHEELER, 2005b; SEIM, 2008; BRISSON, 2010), pediculectomia estendida (SHARP; WHEELER, 2005b; BRISSON, 2010) e pediculectomia parcial (McCARTNEY, 1997; BRISSON, 2010) tem por objetivo realizar a descompressão da medula espinhal por abordagens menos invasivas, pois removem menos osso vertebral. Estes procedimentos são alegadamente mais rápidos, e proporcionam acesso aos aspectos ventrais e laterais do canal medular para remoção do material de disco, criam menos trauma nos tecidos moles e menos instabilidade vertebral, com uma recuperação mais rápida no pósoperatório (BRISSON, 2010). A descompressão cirúrgica proporcionada pela abertura do canal medular, sem remoção adequada do material do disco do interior do canal vertebral não restaura a hemodinâmica arterial e venosa normal e não é considerada ideal (SEIM, 2008; BRISSON, 2010). Assim, o procedimento de corpectomia tem sido recomendado para o tratamento da DDIV tipo II e para os casos crônicos de extrusões tipo I, em que a remoção do disco é susceptível de ser incompleta ou resultar na deterioração significativa do estado neurológico, por causa da encapsulação e aderência do disco na medula espinhal, raiz nervosa e seio venoso (MOISSONNIER; MEHEUST; CARROZO, 2004), podendo ser associada ou não às técnicas menos invasivas anteriormente citadas (FLEGEL et al., 2011; MARINHO, 2013).

\section{Laminectomia Dorsal}

A laminectomia dorsal consiste na remoção da lâmina dorsal da vértebra sem envolvimento dos 
processos articulares, e permite o acesso a ambos os lados do canal vertebral, mas não ao assoalho (REDDING, 1951; SHARP; WHEELER, 2005b); não apresentando na região toracolombar quaisquer vantagens adicionais em relação às demais técnicas, exigindo ainda dissecção muscular mais ampla (TOOMBS; WATERS, 2007). Em cães com DDIV toracolombar foi possível a retirada de material discal do interior do canal toracolombar em 93\% dos cães submetidos à hemilaminectomia, em comparação a $40 \%$ dos cães que passaram por laminectomia dorsal (McKEE, 1992). A remoção eficaz de massa compressiva ventral à medula espinhal toracolombar pode ser problemática na técnica de laminectomia dorsal, mas a técnica parece ser benéfica em cães com compressão medular decorrente de alterações osteoartríticas nas facetas articulares da região cervical (DA COSTA, 2010). Pode ser usada para tratar compressões em várias vértebras cervicais, e uma complicação importante da laminectomia dorsal cervical é a piora do quadro neurológico em até $70 \%$ dos casos (DA COSTA, 2010). Na doença lombo-sacra, a laminectomia dorsal é a melhor opção para descompressão da cauda equina e nervos espinhais, podendo ser combinada com descompressão do forame e estabilização vertebral (SHARP; WHEELER, 2005c).

Em um estudo com cães de grande porte não condrodistróficos, com DDIV toracolombar Hansen tipo II, observou-se que $90 \%$ dos pacientes recuperaram-se bem após a realização da laminectomia dorsal, no entanto, houve um atraso no tempo de recuperação de 5,6 semanas em cães ambulatoriais e sete semanas para os cães não ambulatoriais antes da cirurgia. Quase $40 \%$ dos cães não foram capazes de caminhar normalmente após a cirurgia (CUDIA; DUVAL, 1997). O número significante de cães com locomoção anormal pode estar relacionada com a permanência de material de disco no interior do canal vertebral, lesão medular irreversível associada à compressão crônica, ou a lesão por impacto no momento da ruptura do disco. $\mathrm{O}$ mesmo problema existe na doença crônica do disco Hansen I. A remoção completa do material sem trauma iatrogênico da medula espinal é difícil por causa das aderências entre o disco e as estruturas extradurais. Se o material do disco estiver localizado ventromedialmente ou ventrolateralmente no canal vertebral, a remoção exige manipulação da medula espinhal, o que parece resultar em um estado neurológico significativamente pior depois da cirurgia, e pode contribuir para o aumento do período de hospitalização (MOISSONNIER; MEHEUST; CARROZO, 2004).

\section{Hemilaminectomia}

A técnica cirúrgica de hemilaminectomia consiste na remoção unilateral da lâmina, das facetas articulares e de partes do pedículo das vértebras afetadas (Figura 1A) (BAHR ARIAS et al., 1999; SEIM, 2008). Visto que, em sua maioria, as lesões de disco toracolombar envolvem a presença de massa compressiva ventral ou ventrolateral à medula espinhal (SHARP; WHEELER, 2005b), é preferível a prática da hemilaminectomia, em lugar da laminectomia dorsal (SEIM, 2008). A associação da técnica de fenestração à hemilaminectomia também é mais fácil (SHARP; WHEELER, 2005b).

A hemilaminectomia proporciona descompressão medular satisfatória e fácil acesso ao assoalho do canal vertebral para a remoção atraumática do material discal, e, comparada à laminectomia dorsal, é um procedimento que causa menos instabilidade vertebral (SMITH; WALTER, 1988; BAHR ARIAS et al., 2007; BRISSON, 2010), pois preserva a integridade biomecânica e estrutural da coluna vertebral (SHARP; WHEELER, 2005b), além de reduzir as chances da formação de cicatrizes que causem compressão medular, como a membrana de laminectomia (SHARP; WHEELER, 2005b; TOOMBS; WATERS, 2007; BRISSON, 2010); no entanto, apresenta um risco aumentado de hemorragia do seio venoso em comparação com o procedimento de laminectomia dorsal (BRISSON, 
2010). A abordagem dorsal à coluna vertebral para a realização da hemilaminectomia permite o acesso ao lado contralateral caso seja necessário, sem precisar reposicionar o pacientes durante a cirurgia. O procedimento envolve a remoção das facetas articulares e pode, portanto, levar a algum grau de instabilidade vertebral (SHARP; WHEELER, 2005b).

Figura 1. Imagem fotográfica ilustrativa da hemilaminectomia, com remoção das facetas articulares. Observa-se o processo espinhoso (asterisco branco), medula espinhal (asterisco vermelho) e processos articulares das vértebras adjacentes (asterisco preto) como limite cranial e caudal da hemilaminectomia (A); e Imagem fotográfica ilustrativa da pediculectomia verdadeira (seta preta) com preservação do processo articular (asterisco vermelho) e visualização da medula espinhal (asterisco preto) (B).

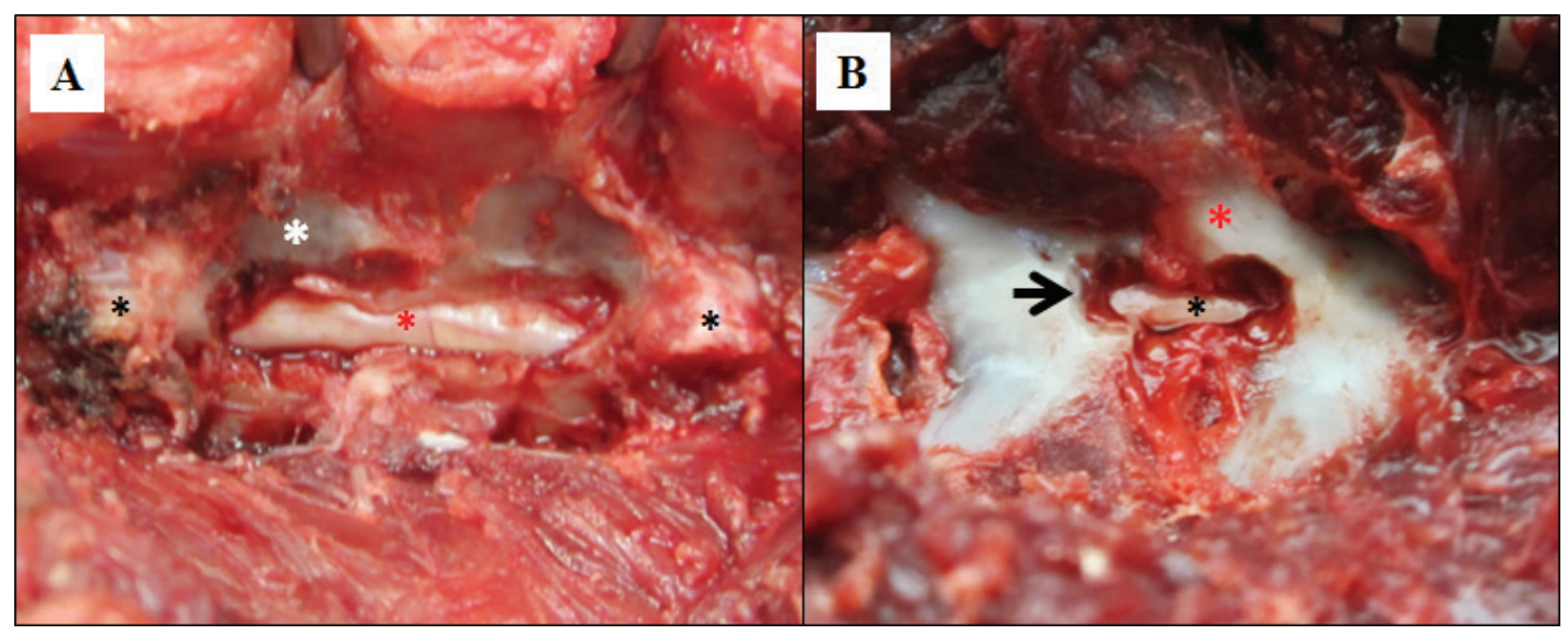

Fonte: Elaboração dos autores.

Em 36 cães não condrodistróficos com DDIV do tipo II, comparou-se a evolução após tratamento cirúrgico em 12 cães e clínico em 20 cães, sendo que outros quatro foram submetidos à eutanásia. Concluiu-se que a técnica de hemilaminectomia não foi superior ao tratamento clínico, pois somente 1/3 dos cães operados apresentou melhora do quadro clínico (MACIAS et al., 2002). Curiosamente estes animais apresentaram quadros neurológicos mais leves, sem paralisia ou incontinência urinária, quando comparado a cães não condrodistróficos com extrusão de disco (MACIAS et al., 2002). Nesse mesmo trabalho, cães não condrodistróficos com DDIV do tipo I apresentaram evolução melhor do quadro após o tratamento cirúrgico, mesmo apresentando quadro neurológico mais grave (MACIAS et al., 2002).
Gaitero e Añor (2009) relatam piora após hemilaminectomia em três cães da raça Pastor Alemão, com ataxia e paresia devido provavelmente à protrusão do disco intervertebral entre a segunda (T2) e terceira (T3) vertebras torácicas, com melhora progressiva e evolução média da recuperação em torno de dois meses após a cirurgia em dois de três desses pacientes, sendo que um deles provavelmente apresentava mielopatia degenerativa e não apresentou recuperação.

Schmied, Golini e Steffen (2011) compararam o resultado do uso da técnica de hemilaminectomia em 41 cães com DDIV cervical, tanto do tipo I como do tipo II. Em 26 cães grandes constataram DDIV do tipo I em 8 cães e a DDIV do tipo II em 18. Em 15 cães pequenos constataram a DDIV do tipo I em 14 pacientes e a DDIV do tipo II em um cão. Nos 
cães grandes com DDIV do tipo II, a evolução foi considerada excelente em oito cães, boa em seis e quatro cães não melhoraram, resultado inferior ao obtido nos cães pequenos, onde 14 apresentaram evolução excelente e um boa (SCHMIED; GOLINI; STEFFEN, 2011). Os autores atribuíram o resultado à dificuldade em retirar todo o material do disco, ao fato da compressão medular ser crônica e ao peso maior dos animais, que ocasionou mais complicações e maior tempo de hospitalização (SCHMIED; GOLINI; STEFFEN, 2011).

Assim, estes procedimentos podem resultar em deterioração pós-operatória ou demora para o retorno da função neurológica. A descompressão medular incompleta para minimizar a manipulação da medula espinhal pode também influenciar negativamente na evolução neurológica (McKEE, 1992; YOVICH; READ; EGER, 1994; COATES, 2000) e segundo Schmied, Golin e Steffen (2011) outros fatores relacionados à piora do quadro são o trauma cirúrgico e a lesão medular por reperfusão.

\section{Pediculectomia}

Há controvérsias quanto às definições dos termos pediculectomia e pediculectomia parcial entre os vários autores consultados (SHARP; WHEELER, 2005b; SEIM, 2008; KERVIN et al., 2012). Ambas são variações da técnica de hemilaminectomia (KERVIN et al., 2012), indicada na região toracolombar (SEIM, 2008). A pediculectomia parcial é chamada também de minihemilaminectomia, sendo a abertura do canal realizada em volta do forame intervertebral (Figura 1B), preservando os processos articulares, o que permite um bom acesso à parte ventral do canal vertebral (LUBBE; KIRBERGER; VERSTRAETE, 1994; SHARP, WHEELER; 2005b). Alguns outros autores denominam essa técnica de pediculectomia (SEIM, 2008). Já outros autores denominam pediculectomia (SHARP; WHEELER, 2005b) ou pediculectomia parcial (KERVIN et al., 2012) a técnica em que a abordagem é realizada sobre o meio do corpo vertebral, evitando a região do forame e seus vasos. Esta abordagem ao meio do corpo da vértebra é limitada, uma vez que a maioria do material discal tende a concentrar-se na região do forame intervertebral. Para melhorar o acesso, pode-se unir duas pediculectomias parciais com uma pediculectomia verdadeira. Esta combinação posteriormente pode estender-se facilmente para uma hemilaminectomia convencional se for necessária exposição adicional (McCARTNEY, 1997; SHARP; WHEELER, 2005b). De qualquer maneira, o que determinará o resultado destas técnicas descompressivas é a capacidade de retirar o material do interior do canal vertebral, e a escolha da técnica depende do conhecimento do tipo de compressão, localização da mesma e da habilidade do cirurgião.

\section{Corpectomia Lateral Parcial}

Os problemas relatados anteriormente, relacionados à dificuldade da remoção do material, principalmente na região toracolombar, tem levado alguns autores (YOVICH; READ; EGER, 1994; BLACK, 1998; SEIM, 2008) a considerar que na extrusão crônica e na protrusão discal "se o material do disco não puder ser facilmente removido durante a cirurgia, o melhor é deixá-lo in situ ao invés de realizar manobras cirúrgicas para sua remoção, o que poderia conduzir a um agravamento do estado neurológico. No melhor dos casos, o anel fibroso hipertrofiado é incisado e parcialmente removido". Isto leva, frequentemente, a remoção incompleta do material de disco estruso e/ou protruído ou mesmo a um elevado risco de trauma medular iatrogênico durante a tentativa de retirada do disco, levando a um agravamento do quadro neurológico do cão (CUDIA; DUVAL, 1997; MOISSONNIER; MEHEUST; CARROZO, 2004). Entretanto, a não retirada de todo material do disco do interior do canal medular após a cirurgia descompressiva também pode causar piora do quadro neurológico (FORTERRE et al., 2010). Assim, na tentativa de 
solucionar este problema, foi proposta a técnica de corpectomia toracolombar.

Esta técnica é realizada por meio de um acesso lateral ou dorsolateral à coluna vertebral e consiste na criação de um "slot" ou fenda lateral através das epífises vertebrais de dois corpos vertebrais adjacentes a um disco intervertebral (Figura 2). Este acesso ventral ao canal vertebral permite a remoção do material do disco e evita o trauma medular adicional. Em um relato inicial com 15 cães de raças pequenas e grandes com doença tipo II tratados por corpectomia, foram observados resultados excelentes, com nenhum dos casos apresentando piora dos sinais clínicos, havendo melhora do quadro neurológico após o procedimento em todos os cães (MOISSONNIER; MEHEUST; CARROZO, 2004).

Figura 2. Imagem fotográfica ilustrativa da corpectomia lateral parcial (CLP). Vista lateral da corpectomia toracolombar lateral (seta cheia): o slot lateral foi realizado abaixo do material prolapsado através do disco intervertebral e das epífises vertebrais de dois corpos vertebrais adjacentes. A excisão do disco protruído foi finalizada quando a medula espinhal (flecha) retornou a sua posição normal. Asterisco vermelho: processo articular. Asterisco preto: processo acessório.

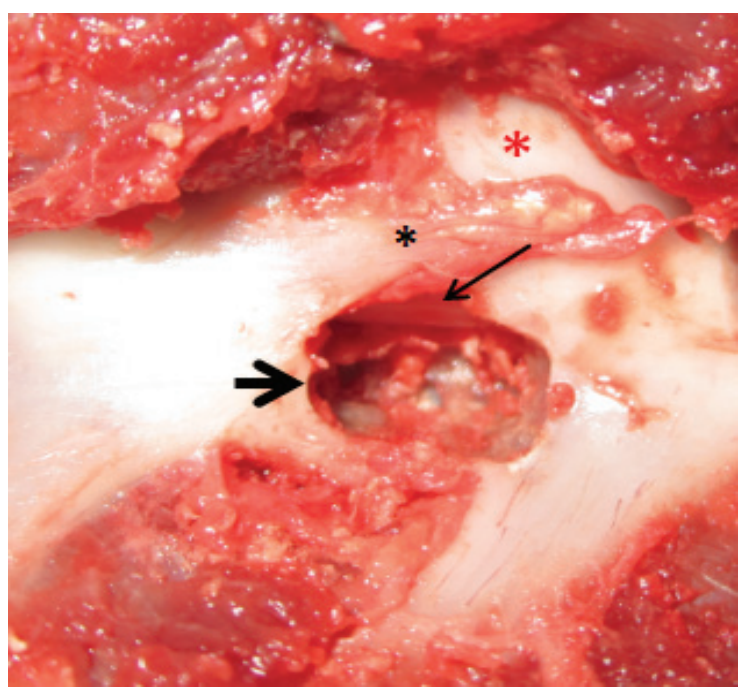

Fonte: Elaboração dos autores.

Para Moissonnier, Meheust e Carrozo (2004), quando há protrusão ventral mediana ou ventrolateral, a medula espinhal pode adquirir um formato sobre o disco saliente, criando o que se chama de efeito "embalagem", que esconde o material protruído, o qual não pode ser visualizado a partir de uma abordagem dorsal ou dorsolateral. Assim, a corpectomia lateral parcial cumpre três objetivos principais para o tratamento cirúrgico da DDIV Hansen II e Hansen I crônica, que são permitir a remoção do material do disco prolapsado e assim a descompressão medular adequada, evitar lesão iatrogênica da medula espinhal durante a remoção do material de disco e permitir o uso de fenestração profilática eficiente do disco (MOISSONNIER; MEHEUST; CARROZO, 2004).

Segundo Flegel et al. (2011), a corpectomia lateral parcial é uma técnica desafiadora, principalmente quando realizada por uma abordagem lateral. Se o material do disco não puder ser removido de forma satisfatória, é possível a descompressão adicional da medula espinhal e a remoção do disco remanescente utilizando concomitantemente a pediculectomia (Figura 3), foraminotomia ou hemilaminectomia. Segundo os mesmos autores, estas combinações de técnicas também podem ser utilizadas para investigar suspeita de mielomalácia e/ou realizar durotomia. Rocha et al. (2012) e Marinho (2013) optaram por realizar uma pediculectomia previamente à realização da corpectomia, para observar o interior e o assoalho do canal medular, tendo em vista o grau de complexidade já relatada por cirurgiões experientes durante a realização da corpectomia lateral parcial. Rocha et al. (2012) e Marinho (2013) citam que é difícil o direcionamento do "slot" a ser criado, pela limitada visualização das estruturas anatômicas que guiam o cirurgião, o que exige um posicionamento perfeito do paciente na mesa, grande destreza e experiência do cirurgião. Nesses estudos, a pediculectomia permitiu completa visualização do assoalho do canal vertebral, e esse foi utilizado como referência para direcionar a fresagem durante a realização da corpectomia lateral parcial. 
Figura 3. Imagem fotográfica trans-operatória da corpectomia lateral parcial (seta vermelha) associada à pediculectomia (seta preta) com visualização da medula espinhal (estrela) descomprimida e preservação da faceta articular (asterisco).

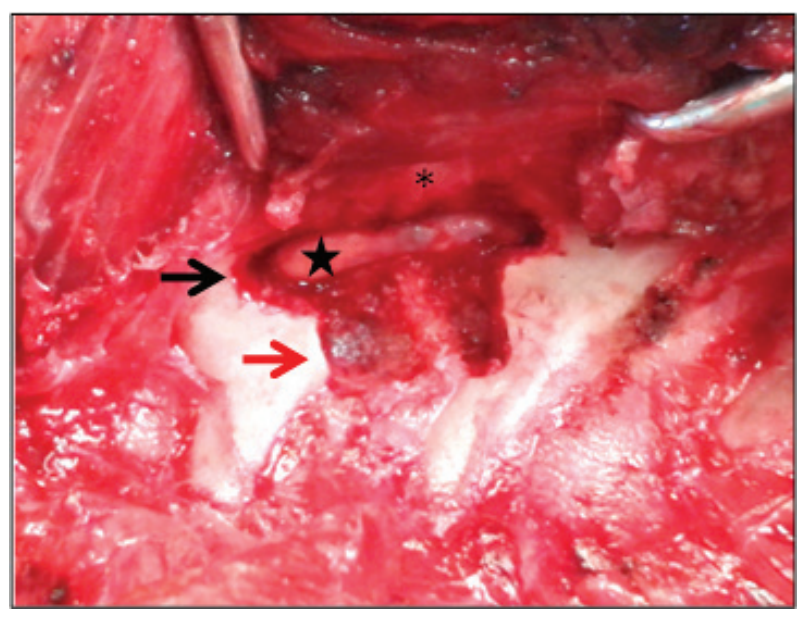

Fonte: Elaboração dos autores.

Em um estudo recente em cães foi avaliada a interferência biomecânica que a corpectomia isolada ou associada com hemilaminectomia exerce sobre a coluna vertebral. Nos resultados do estudo concluiu-se que a corpectomia lateral parcial isolada leva a alguma instabilidade vertebral, e apenas as forças de torção axial e cisalhamento lateral não foram afetadas pelo procedimento (REVÉS et al., 2011). Segundo estes autores, isso aconteceu pelo fato do disco não ter sido completamente removido, pois de acordo com Takeuchi et al. (1999), o disco intervertebral desempenha um importante papel na estabilidade em relação as forças de flexão/extensão, flexão lateral e torção axial.

Segundo Revés et al. (2011), se a técnica de hemilaminectomia for adicionada à técnica de corpectomia lateral parcial, a visualização da medula espinhal pode melhorar drasticamente, porém produz um agravamento significativo na instabilidade da coluna durante flexão/extensão, rotação axial, dorsal/ventral e movimento de cisalhamento lateral. A perda de massa óssea resultante da combinação de corpectomia e hemilaminectomia, somada à perda de uma das facetas articulares explica esses resultados. Embora a hemilaminectomia não tenha um efeito desestabilizador durante flexão/extensão quando testada isoladamente (CORSE; RENBERG; FRIISE, 2003), esse afeito existe quando combinada à corpectomia. Segundo Rocha et al. (2012) e Marinho (2013), a técnica de pediculectomia associada à corpectomia lateral parcial, com preservação das facetas articulares, não demostrou instabilidade nas avaliações clínica e radiográfica, sendo justificado pelo fato das facetas articulares desempenharem um papel importante em resistir ao cisalhamento ventral/dorsal e forças de torção (NG et al., 2003).

A técnica de corpectomia lateral parcial foi utilizada em um gato no tratamento de protrusão do disco intervertebral ao nível de T2 e T3 com evolução favorável do quadro neurológico em oito semanas (BOTTCHER et al., 2008). Para estes autores, apesar da variação anatômica entre o cão e o gato, a técnica deve ser realizada de modo semelhante ao realizado cães, diferindo apenas no percentual de retirada do osso.

Em 331 cães foi descrita uma técnica de discectomia percutânea parcial, anatomicamente comparável com uma corpectomia, porém de menor tamanho, constatando-se uma taxa de 88,8\% de recuperação para os pacientes que tinham dor profunda preservada, com um tempo médio para melhora de 8,3 dias. A discectomia percutânea foi desprovida de sucesso em cães sem nocicepção profunda (KINZEL et al., 2005).

\section{Estabilização Vertebral}

O uso da técnica de estabilização vertebral foi relatada por Slocum e Devine (1986) e Bruecker, SeimeBlass(1989)especificamentepara os pacientes com protrusão do disco intervertebral causando síndrome da cauda equina e espondilomielopatica cervical, respectivamente. Segundo Macias et al. (2002), o papel de estabilização cirúrgica da vértebra afetada ainda não está claro, embora tenha 
sido sugerido como uma medida útil para prevenir protrusão adicional. Para estes autores, estudos prospectivos com um maior número de casos são necessários para determinar o real valor da estabilização vertebral.

Em estudo realizado por Mckee e Downes (2008) protrusões triplas adjacentes na região toracolombar causando compressão da medula espinhal foram diagnosticadas por meio da ressonância magnética em dois cães da raça Pastor Alemão com sinais neurológicos de paraparesia, ataxia proprioceptiva e hiperalgesia na região toracolombar. O tratamento instituído foi descompressão através de hemilaminectomia seletiva associada à anulectomia e estabilização com placa SOP (String of Pearls) fixada em quatro corpos vertebrais consecutivos. Este tipo de implante permitiu moldagem com maior grau de liberdade facilitando a fixação na região toracolombar. Observou-se que ambos os cães tratados cirurgicamente apresentaram ausência de dor espinhal e melhora progressiva lenta dos sinais neurológicos, porém déficits neurológicos persistentes foram observados em ambos os cães. De acordo com o estudo, a descompressão medular provavelmente foi incompleta, mas a estabilização vertebral pode ter desempenhado um papel importante, pois a estabilidade conferida pela placa vertebral no corpo evitou protrusão adicional dos discos, preveniu a compressão dinâmica da medula espinhal e promoveu atrofia do disco intervertebral a longo prazo. Relata-se atrofia do material discal anular na coluna cervical de cães após distraçãoestabilização (McKEE et al., 1990). Segundo Mckee e Downes (2008), o papel relativo da descompressão medular e estabilização vertebral são especulativos, e o potencial de atrofia do anel fibroso em longo prazo, secundário a estabilização, não foi determinado.

Um segundo experimento foi realizado por Downes et al. (2009) para avalizar a eficácia da estabilização vertebral no tratamento da protrusão do disco intervertebral toracolombar em 28 cães. O critério utilizado para identificar a protrusão foi a mielografia. As estabilizações foram realizadas com placas e parafusos ou parafusos e cimento ósseo inseridos em um ângulo de 40 a 50 graus ao eixo vertical do corpo vertebral. A idade média dos pacientes foi de oito anos, sendo que a raça Pastor Alemão e mestiços foram as mais acometidas. No dia do atendimento, 22 cães eram ambulatoriais e seis não ambulatoriais sendo que 17 apresentavam hiperestesia na região toracolombar. A principal complicação da técnica foi laceração do seio venoso vertebral. No exame neurológico 24 horas após a cirurgia observou-se deterioração neurológica em 17 cães e função neurológica inalterada nos demais. Melhora na função neurológica foi evidente em 21 de 24 cães no acompanhamento em longo prazo, dois cães permaneceram com estado neurológico inalterado e em um deles houve piora. No resultado final, 13 cães foram considerados normais e onze paraparéticos.

Segundo Downes et al. (2009), a recuperação neurológica incompleta pode ter sido devido à atrofia medular pela cronicidade da compressão ou por descompressão medular incompleta. A hemilaminectomia e estabilização vertebral foram eficazes no tratamento de hiperestesia em 12 dos 13 cães acompanhados a longo prazo. O próprio autor (DOWNES et al., 2009) relata as limitações desse estudo prospectivo: potencial erro na seleção dos casos, pois afecções medulares concomitantes como mielopatia isquêmica, embolismo fibrocartilaginoso e mielopatia degenerativa não foram excluídos; a RM não foi realizada, sendo este o método ideal para verificar alterações do parênquima medular; os casos foram avaliados por diferentes veterinários e a avaliação do grau das disfunção neurológica pode ter sido subjetiva. Além disso, o sistema de classificação da disfunção neurológica não foi validado, uma vez que o sistema mais objetivo é o relatado por Olby et al. (2001), além do fato da a avaliação a longo prazo ter sido realizada por telefone. 


\section{Considerações Finais}

O principal ponto que deve ser questionado na DDIV tipo II é quanto ao tipo de compressão, uma vez que baseado na fisiopatologia da compressão medular crônica, a degeneração axonal e malácia podem ser irreversíveis independente do tipo de cirurgia realizada (KANCHIKU et al., 2001; MACIAS et al., 2002; OLBY, 2010). A doença do disco intervertebral crônica representa um desafio em termos de tratamento, principalmente por que em muitos casos não se sabe exatamente o significado clínico da compressão, podendo haver ainda a existência de doenças medulares concomitantes, como a mielopatia degenerativa, principalmente em cães com DDIV tipo II toracolombar. As aderências do material do disco à dura-máter ou seios venosos requerem maior manipulação da medula espinhal, o que pode resultar em deterioração neurológica pósoperatória ou demora para o retorno da função. Não obstante, a descompressão medular incompleta para minimizar a manipulação da medula espinhal pode também influenciar negativamente na evolução neurológica (McKEE, 1992; YOVICH; READ; EGER, 1994; COATES, 2000).

Outro fator que parece comprometer a evolução de cães de raças grandes é o manejo pósoperatório, visto que estes cães são mais difíceis de lidar do que cães pequenos, pois exigem maior esforço na fisioterapia, cuidados de enfermagem, esvaziamento vesical, além de desenvolverem úlceras de pressão mais facilmente (KERWIN; LEVINE; HICKS, 2012).

Assim, mais estudos devem ser realizados em cães com a DDIV tipo II, para analisar o significado clínico real das compressões medulares observadas, para que o benefício de novas técnicas como a corpectomia e a estabilização vertebral sejam realmente comprovadas. Necessita-se ainda de maior padronização das escalas de avaliação da locomoção dos animais aliado a maior objetividade na avaliação da evolução dos pacientes, como com o uso de análise cinemática da locomoção (KERWIN; LEVINE; HICKS, 2012).

\section{Referências}

AMORT, K. H.; ONDREKA, N.; RUFORF, H.; STOCK, K. F.; DISTL O.; TELLHELM, B.; KRAMER M.; WIGGER, A. MR-Imaging of lumbosacral intervertebral disc degeneration in clinically sound german shepherd dogs compared to other breeds. Veterinary Radiology \& Ultrasound, Virginia, v. 53, n. 3, p. 289-295, 2012.

BAHR ARIAS, M. V.; ANDRADE, F. R.; BAHR, S. E.; BARROS, M. Y.; CAMPOS, S.; MORENO, K. Hemilaminectomia para tratamento da doença de disco toracolombar em cães. Estudo retrospectivo. In: CONGRESSO BRASILEIRO DA ANCLIVEPA, 20., 1999, Águas de Lindóia. Anais... Águas de Lindóia 1999. p. 35-35.

BAHR ARIAS, M. V.; SEVERO, M. S.; TUDURY, E. A. Trauma medular em cães e gatos: revisão da fisiopatogenia e do tratamento médico. Semina: Ciências Agrárias, Londrina, v. 28, n. 1, p. 115-134, 2007.

BAHR ARIAS, M. V.; NISHIOKA, C. M.; GARCIA, C. O.; REIA, A. Z.; BARAÚNA JÚNIOR, D.; MARCASSO, R. A. Avaliação dos resultados clínicos após cirurgia descompressiva em cães com doença de disco intervertebral. Arquivo Brasileiro de Medicina Veterinária e Zootecnia, Belo Horizonte, v. 59, n. 6, p. 1445-1450, 2007.

BERGKNUT, N.; SMOLDERS, L. A.; GRINWIS, G. C. M.; HAGMAN, R.; LAGERSTEDT, A. S.; HAZEWINKEL, H. A. W.; TRYFONIDOU, M. A.; MEIJ, B. P. Intervertebral disc degeneration in the dog. Part 1: anatomy and physiology of the intervertebral disc and characteristics of intervertebral disc degeneration. The Veterinary Journal, London, v. 195, n. 3, p. 282-291, 2013.

BITTELO, W. F.; THACHER, C. A. Modified lateral decompression for treatment of canine intervertebral disc disease. Journal of the American Animal Hospital Association, Denver, v. 23, p. 409, 1987.

BLACK, A. P. Lateral spinal decompression in the dog: a review of 39 cases. Journal Small Animal Practice, Ontario, v. 29, n. 9, p. 581-588, 1988.

BLIGHT, A. R. New drugs for spinal trauma. In: AMERICAN COLLEGE OF VETERINARY INTERNAL MEDICINE FORUM, 18., 2000, Seattle. Proceedings... Seattle: [s.n], 2000. p. 292-293.

BOTTCHER, P.; FLEGEL, T.; BOTTCHER, I. C.; 
GREVEL, V.; OECHTERING, G. Partial lateral corpectomy for ventral extradural thoracic spinal cord compression in a cat. Journal of Feline Medicine and Surgery, Vancouver, v. 10, n. 3, p. 291-295, 2008.

BRAUND, K. G. Moléstia do disco intervertebral. In: BOJRAB, J. M. Mecanismos da moléstia na cirurgia dos pequenos animais. 2. ed. São Paulo: Manole, 1996. p. 1104-1116.

BRAY, J. P.; BURBRIDGE, H. M. The canine intervertebral disk. Part one: structure and function. Journal of the American Animal Hospital Association, Denver, v. 34, n. 1, p. 55-63, 1998a.

The canine intervertebral disc. Part two: degenerative changes - nonchondrodystrophoid versus chondrodystrophoid disks. Journal of the American Animal Hospital Association, Denver, v. 34, n. 2, p. 135144, 1998b.

BRISSON, B. A. Intervertebral disc disease in dog. Veterinary Clinics of North America. Small Animal Practice, Philadelphia, v. 40, n. 5, p. 829-858, 2010.

BRUECKER, K. A.; SEIM, H. B.; BLASS, C. E. Caudal cervical spondylomyelopathy: decompression by linear traction and stabilisation with Steinmann pins and polymethyl methacrylate. Journal of the American Animal Hospital Association, Denver, v. 25, n. 6, p. 677683, 1989.

CHAN, W.; LIN, J. H.; ROGERS, P. A. M. A review of acupuncture therapy of canine paralysis and lameness. Veterinary Bulletin, Farnham Royal, v. 66, n. 10, p. 9991011, 1996.

COATES, J. R. Intervertebral disk disease. Veterinary Clinics of North America Small Animal Practice, Philadelphia, v. 30, n. 1, p. 77-93, 2000.

Paraparesis. In: PLATT, S. R.; OLBY, N. J. $\overline{\text { British }}$ small animal veterinary association manual of canine and feline neurology. 3. ed. Quedgeley: BSAVA, 2004. p. 237-264.

CORSE, M. R.; RENBERG, W. C.; FRIISE, A. In vitro evaluation of biomechanical effects of multiple hemilaminectomies on the canine lumbar column. American Journal of Veterinary Research, Chicago, v. 64, n. 9, p. 1139-45, 2003.

CUDIA, S. P.; DUVAL, J. M. Thoracolumbar intervertebral disk disease in large, non chondrodystrophic dogs: a retrospective study. Journal of the American Animal Hospital Association, Denver, v. 33, n. 5, p. 456460, 1997.

DA COSTA, R. C. Disco intervertebral: bases para o diagnóstico e tratamento da doença. Nosso Clinico, São
Paulo, v. 4, n. 20, mar./abr. 2001.

Cervical spondylomyelopathy (wobbler syndrome) in dogs. Veterinary Clinics of North America. Small Animal Practice, Philadelphia, v. 40, n. 5, p. 881913, 2010.

DE LAHUNTA, A.; GLASS, E. Small animal spinal cord disease. In:__. Veterinary neuroanatomy and clinical neurology. 4. ed. Philadelphia: Saunders Elsevier, 2009. cap. 10, p. 257-259.

DEWEY, C. W. Myelopathies: disorders of the spinal cord. In: A practical guide to canine and feline neurology. 2. ed. Iowa: Wiley-Blackwell, 2008. cap. 10, p. 323-388.

DOWNES, C. J.; GEMMILL, T. J.; GIBBONS, S. E.; MCKEE, W. M. Hemilaminectomy and vertebral stabilisation for the treatment of thoracolumbar disc protrusion in 28 dogs. Journal of Small Animal Practice, Ontario, v. 50, n. 10, p. 525-535, 2009.

FLEGEL, T.; BOETTCHER, I. C.; LUDEWIG, E.; KIEFER, I.; OECHTERING, G.; BOTTCHER, P. Partial lateral corpectomy of the thoracolumbar spine in 51 dogs: assessment of slot morphometry and spinal cord decompression. Veterinary Surgery, Davis, v. 40, n. 1, p. 14-21, 2011.

FORTERRE, F.; GORGAS, D.; DICKOMEIT, M.; JAGGY, A.; LANG, J.; SPRENG, D. Incidence of spinal compressive lesions in chondrodystrophic dogs with abnormal recovery after hemilaminectomy for treatment of thoracolumbar disc disease: a prospective magnetic resonance imaging study. Veterinary Surgery, Davis, v. 39, n. 2, p. 165-72, 2010.

GAITERO, L.; AÑOR, S. Cranial thoracic disc protrusions in three German Shepherd dogs. The Veterinary Journal, London, v. 182, n. 2, p. 349-51, 2009.

HANSEN, H. J. A pathology-anatomical study on disc degeneration in the dog. Acta Orthopaedica Scandinavica Supplementum, Copenhagem, v. 11, p. 1-117, 1952.

Pathogenesis od disc degeneration and rupture. In: GHERY, D. P. Intervertebral disc protrusion in the dog. New York: Appleton-Century-Crofts, 1966. cap. 2, p. 21-50.

HASHIMOTO, K.; AKAHORI, O.; KITANO, K.; NAKAJIMA, K.; HIGASHIHARA, T.; KUMASAKA, Y. Magnetic resonance imaging of lumbar disc herniation: comparison with myelography. Spine, Philadelphia, v. 15, n. 11, p. 1166-1169, 1990.

INOUE, $\mathrm{H}$. Three dimensional architecture of lumbar intervertebral disks. Spine, Philadelphia, v. 6, n. 2, p. 139-146, 1981. 
JEFFERY, N. D. Pathophysiology of spinal cord injury. In: Handbook of small animal spinal surgery. London: Saunders, 1995. cap. 5, p. 64-71.

Tratment of acute and cronic thoracolumbar disc disease by "mini" hemilaminectomy. Journal Small Animal Practice, Ontario, v. 29, n. 9, p. 611, 1988.

KANCHIKU, T.; TAGUCHI, T.; KANEKO, K.; YONEMURA, H.; KAWAI, S.; GONDO, T. A new rabbit model for the study on cervical compressive myelopathy. Journal of Orthopaedic Research, New York, v. 19, n. 4, p. 605-613, 2001.

KERWIN, S. C.; LEVINE, J. M.; HICKS, D. G. Thoracolumbar spine. In: TOBIAS, K. M.; JOHNSTON, S. A. Veterinary surgery. Small animal. Missouri: Elsevier Saunders, 2012. v. 1, p. 449-475.

KINZEL, S.;WOLFF, M.;BUECKER,A.; KROMBACH, G.A.; STOPINSKI, T.; AFIFY, M.; WEISS, C.; KUPPER, W. Partial percutaneous discectomy for treatment of thoracolumbar disc protrusion: retrospective study of 331 dogs. Journal Small Animal Practice, Ontario, v. 46, n. 10, p. 479-484, 2005.

KRANENBURG, H. C.; GRINWIS, G. C. M.; BERGKNUT, N.; GAHRMANN, N.; VOORHOUT, G.; HAZEWINKEL, H. A. W.; MEIJ, B. P. Intervertebral disc disease in dogs - Part 2: Comparison of clinical, magnetic resonance imaging, and histological findings in 74 surgically treated dogs. The Veterinary Journal, London, v. 195, n. 2, p. 164-171, 2013.

KRAUS, K. H. Medical management of acute spinal cord disease. In: KIRK, R. W. Current veterinary therapy XIII: small animal practice. Philadelphia: Saunders, 2000. p. 186-190.

LE COUTEUR, R. A.; GRANDY, J. L. Doenças da medula espinhal. In: ETTINGER, S. J.; FELDMAN, E. C. Tratado de medicina interna veterinária - doenças do cão e do gato. 5. ed. Guanabara Koogan: Rio de Janeiro, 2004. v. 1, p. 667-672.

LEVINE, G. J.; LEVINE, J. M.; WALKER, M. A.; POOL, R. R.; FOSGATE, G. T. Evaluation of the association between spondylosis deformans and clinical sign of intervertebral disk disease in dogs: 172 cases (1999-2000). Journal of the American Veterinary Medical Association, Chicago, v. 228, n. 1, p. 96-100, 2006.

LORENZ, M. D.; KORNEGAY, J. N. Paresia, paralisia e ataxia do membro pélvico. In: Neurologia veterinária. 4. ed. Manole: São Paulo, 2006. v. 1, p. 131168.

LUBBE, A. M.; KIRBERGER, R. M.; VERSTRAETE, F. J. M. Pediculectomy for thoracolumbar spinal decompression in the dachshund. Journal of the American Animal Hospital Association, Denver, v. 30, n. 3, p. 233238, 1994.

MACIAS, C.; McKEE, W. M.; MAY, C.; INNES, J. F. Thoracolumbar disk disease in large dogs: a study of 99 cases. Journal Small Animal Practice, Ontario, v. 43, n. 10, p. 439-446, 2002.

MARINHO, P. V. T. Corpectomia lateral parcial associada à pediculectomia no tratamento de discopatia toracolombar crônica em cães. 2013. Monografia (Monografia apresentada ao Programa de Aprimoramento Profissional, Área de Clínica Cirúrgica de Pequenos Animais, da Universidade Estadual Paulista Júlio de Mesquita Filho, Jaboticabal.

McCARTNEY, W. Partial pediculectomy for the treatment of thoracolumbar disc disease. Veterinary and Coparative Orthopaedics and Traumatology, Stuttgart, v. 10, n. 2, p. 117, 1997.

McKEE, W. M. A comparison of hemilaminectomy (with concomitant disc fenestration) and dorsal laminectomy for the treatment of thoracolumbar disc protrusion in dogs. Veterinary Record, London, v. 130, n. 14, p. 296300, 1992.

McKEE, W. M.; DOWNES, C. J. Vertebral stabilisation and selective decompression for the management of triple thoracolumbar disc protrusions. Journal of Small Animal Practice, Ontario, v. 49, n. 10, p. 536-539, 2008.

McKEE, M.; LAVELLE, R. B.; RICHARDSON, J. L.; MASON, T. A. Vertebral distraction-fusion for cervical spondylopathy using a screw and double washer technique. Journal of Small Animal Practice, Ontario, v. 31, n. 1, p. 22-27, 1990.

MOISSONNIER, P.; MEHEUST, P.; CAROZZO, C. Thoracolumbar lateral corpectomy for treatment of chronic disc herniation: technique description and use in 15 dogs. Veterinary Surgery, Davis, v. 33, n. 6, p. 620628, 2004.

MUSK, G.; RAISIS, A. Analgesia for patients with neurological disease. In: PLAT, S.; GAROSI, L. Small animal neurological emergencies. Manson Publishing, 2012. p. 557-569.

NG, H. W.; TEO, E. C.; LEE, K. K.; QIU, T. X. Finite element analysis of cervical spinal instability under physiologic loading. Journal of Spinal Disorders \& Techniques, Hagerstown, v. 16, n. 1, p. 55-65, 2003.

OLBY, N.; JEFFERY, N. Pathogenesis and physiology of central nervous system disease and injury. In: TOBIAS, K. M.; JOHNSTON, S. A. Veterinary surgery. Small animal. Missouri: Elsevier Saunders, 2012. v. 1, p. 374-387. 
OLBY, N.; DE RISIO, L.; MUÑANA, K. R.; WOSAR, M. A.; SKEEN, T. M.; SHARP, N. J. H.; KEENE, B. W. Development of a functional scoring system in dogs with acute spinal cord injuries. American Journal of Veterinary Research, Chicago, v. 62, n. 10, p. 1624-28, 2001.

OLBY, N. The Pathogenesis and treatment of acute spinal cord injuries in dogs. Veterinary Clinics of North America. Small Animal Practice, Philadelphia, v. 40, n. 5, p. 791-807, 2010.

PLATT, S. R.; ABRAMSON, C. J.; GAROSI, L. S. Administering corticosteroids in neurologic diseases. Compendium on Continuing Education in the Practicing Veterinarian, v. 27, n. 3, p. 210-220, 2005.

REDDING, R. W. Laminectomy in the dog. American Journal of Veterinary Research, Chicago, v. 12, n. 43, p. 123-128, 1951.

REVÉS, N. V.; BURKI, A.; FERGUSON, S.; GEISSBUHLER, U.; STAHL, C.; FORTERRE, F. Influence of partial lateral corpectomy with and without hemilaminectomy on canine thoracolumbar stability: a biomechanical study. Veterinary Surgery, Davis, v. 41, n. 2, p. 1-7, 2011.

ROCHA, A. G.; MORATO, G. O.; CHUNG, D. G.; PADILHA FILHO, J. G. Corpectomia lateral associada à pediculectomia para tratamento de discopatia toracolombar crônica em cães. Estudo de 27 casos. In: CONGRESSO BRASILEIRO DE CIRURGIA E ANESTESIOLOGIA VETERINÁRIA,10., Florianópolis. Anais... Florianópolis: [s.n.], 2012.

SEIM, H. B. III. Cirurgia da coluna toracolombar. In: FOSSUM, T. W. Cirurgia de pequenos animais. Rio de Janeiro: Elsevier, 2008. p. 1460-1480.

SCHMIED, O.; GOLINI, L.; STEFFEN, F. Effectiveness of cervical hemilaminectomy in canine Hansen type I and type II disc disease: a retrospective study. Journal of the American Animal Hospital Association, Denver, v. 47, n. 5, p. 342-350, 2011.

SHARP, N. J. H.; WHEELER, S. J. Functional anatomy. In:__. Small animal spinal disorders. Diagnosis and surgery. Edinburgh: Elsevier Mosby, 2005a. p. 1-17.

Thoracolumbar disc disease. In: Small

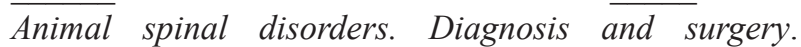
Edinburgh: Elsevier Mosby, 2005b. p. 121-159.
. Lumbosacral disease. In: Small animal spinal disorders. Diagnosis and surgery. Edinburgh: Elsevier Mosby, 2005c. p. 181-09.

SLOCUM, B.; DEVINE, T. L7-S1 fixation-fusion for treatment of cauda equina compression in the dog. Journal of the American Veterinary Medical Association, Chicago, v. 188, n. 1, p. 31-35, 1986.

SMITH, G. K.; WALTER, M. C. Spinal decompressive procedures and dorsal compartment injuries: comparative biomechanical study in canine cadavers. American Journal of Veterinary Research, Chicago, v. 49, n. 2, p. 266, 1988.

SMOLDERS, L. A.; BERGKNUT, N.; GRINWIS, G. C. M.; HAGMAN, R.; LAGERSTEDT, A. S.; HAZEWINKEL, H. A. W.; TRYFONIDOU, M. A.; MEIJ, B. P. Intervertebral disc degeneration in the dog. Part 2: chondrodystrophic and non-chondrodystrophic breeds. The Veterinary Journal, London, v. 195, n. 3, p. 292-299, 2013.

TAYLOR, S. M. Distúrbios da medula espinhal. In: NELSON, R. W.; COUTO, C. G. Medicina interna de pequenos animais. 4. ed. Rio de Janeiro: Elsevier, 2010. cap. 70, p. 1073-1079.

TAKEUCHI, T.; ABUMI, K.; SHONO, Y.; ODA, I.; KENADA, K. Biomechanical role of the intervertebral disc and costovertebral joint in stability of the thoracic spine. A canine model study. Spine, Philadelphia, v. 24, n. 14, p. 1414-1420, 1999.

TOOMBS, J. P.; WATERS, D. J. Afecção do disco intervertebral. In: SLATTER, D. Manual de cirurgia de pequenos animais. 3. ed. São Paulo: Manole, 2007. v. 1, p. 1193-1208.

XU, P.; GONG, W. M.; ZHANG, T.; ZHANG, K.; YIN, D. Z.; JIA, T. H. Destructive pathological changes in the rat spinal cord due to chronic mechanical compression: Laboratory investigation. Journal of Neurosurgery Spine, Charlottesville, v. 8, n. 3, p. 279-285, 2008.

YOVICH, J. C.; READ, R.; EGER, C. Modified lateral spinal decompression in 61 dogs with thoracolumbar disk protrusion. Journal Small Animal Practice, Ontario, v. 35, n. 7, p. 351-356, 1994. 
